Thorax (1976), 31, 113.

\title{
Mitral incompetence and ventricular septal defects following non-penetrating injury
}

\author{
C. H. A N Y A N W U1 \\ Cardiothoracic Surgical Unit, Harefield Hospital, Harefield, Middlesex
}

\begin{abstract}
Anyanwu, C. H. (1976). Thorax, 31, 113-117. Mitral incompetence and ventricular septal defects following non-penetrating injury. A case of mitral incompetence and multiple ventricular septal defects following a non-penetrating chest injury is described. Cardiac injury was detected by electrocardiogram and by the appearance of a heart murmur in the second week after trauma. Superimposition of bacterial endocarditis seven years later caused cardiac decompensation and necessitated successful surgical treatment. Previous reported cases are reviewed.
\end{abstract}

Blunt chest injuries of varying severity have been recognized both experimentally (Kissane, Fidler, and Koons, 1937) and clinically (Warburg, 1940; McLaughlin et al., 1964) as causes of major acquired heart disease. The mechanism of the external injuries varies from relatively minor blows to the chest to severe crushing or compression injuries which result from automobile accidents or injuries of war. The consequent cardiac injuries are also variable-from transient arrythmias to fatal cardiac ruptures. Severe cardiac contusion or rupture can occur without any significant detectable chest wall injury and without fracture of the ribs (Bright and Beck, 1935; Warburg, 1940). Mitral valve damage is not a common complication of non-penetrating chest injury; it was found in association with other cardiac injuries in only eight out of 546 cases reported by Parmley, Manion, and Mattingly (1958). Ventricular septal defect following blunt chest injury has been more frequently reported, but in a recent review (Moraes et al., 1973) of operated cases of ventricular septal defect due to non-penetrating trauma, no associated mitral valve damage was encountered.

\section{CASE REPORT}

A 30-year-old male lorry driver fell off his lorry in 1964 (at the age of 21 years) and landed face downwards. A cannister of bottles weighing about $75 \mathrm{~kg}$ fell from the lorry onto the back of his chest as he was prostrate. He was semiconscious and mildly dyspnoeic, but no external injuries or rib fractures were sustained. He was admitted to hospital and kept

1Present address: Cardiothoracic Unit, Department of Surgery, University of Nigeria Teaching Hospital, Enugu, Nigeria under observation for about six weeks. Radiological examinations confirmed the absence of bony or soft tissue chest wall injury. A murmur of mitral incompetence was, however, detected about two weeks after admission, and an electrocardiogram showed evidence of a posterolateral myocardial infarction which was confirmed with cardiac enzyme studies. No heart murmur had previously been observed; he was medically graded $\mathrm{A} 1$ in the army at the age of 17 years.

Clinical assessment in July 1965 at another hospital revealed a moderately severe mitral pansystolic murmur, a third heart sound, and a short mitral diastolic murmur; the cardiothoracic ratio was 0.49 and an electrocardiogram showed sinus arrhythmia with left ventricular hypertrophy. Cardiac catheterization confirmed 'mitral incompetence with no intracardiac shunt', but cineangiocardiography could not be obtained due to technical difficulties. As he was asymptomatic, he was advised to return for review in six months. In May 1968 he remained asymptomatic. An electrocardiogram showed no deterioration since 1965 , and the chest radiograph showed a cardiothoracic ratio of 0.47 , no pulmonary venous congestion, and no left atrial enlargement. Operation was considered not to be indicated.

However, in July 1972 he was admitted to hospital with bacterial endocarditis due to Streptococcus viridans. He denied a history of recent dental treatment or sore throat, but dental examinations revealed some infection. He was successfully treated with penicillin and streptomycin. There was no immediate evidence of increased mitral regurgitation as a result of the endocarditis. Therefore surgical treatment was not immediately recommended. He remained well 


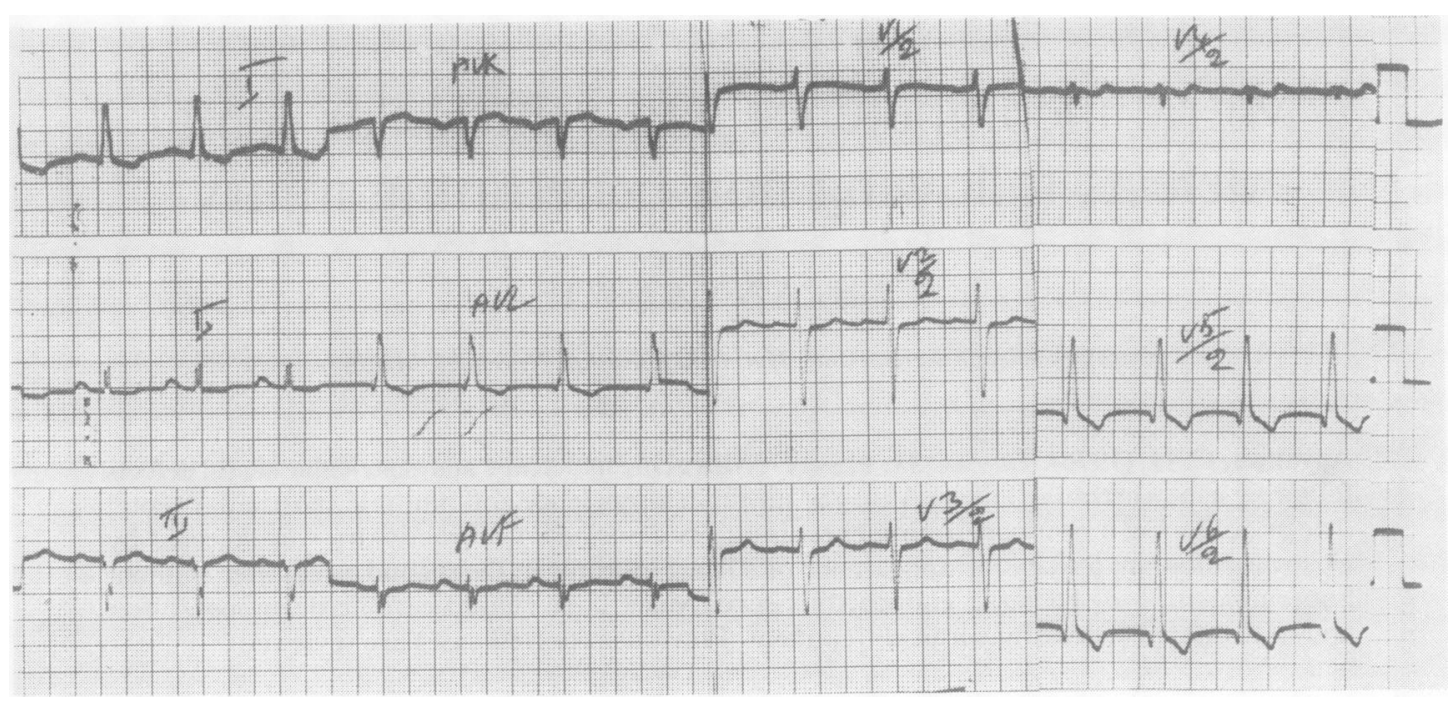

FIG. 1. Preoperative electrocardiogram (see text).

until February 1973 (nine years after the chest injury) when he developed evidence of congestive heart failure. Medical treatment was begun with initial good response, but in view of the onset of cardiac decompensation he was referred to Harefield Hospital for surgical treatment. Clinical examination on this occasion revealed an apical systolic thrill, left ventricular enlargement, a loud apical pansystolic murmur conducted to the axilla, and a moderately loud pansystolic murmur maximal over the left sternal edge and on expiration. An electrocardiogram (Fig. 1) showed sinus rhythm, left ventricular hypertrophy, partial left bundle-branch block, and a mean frontal QRS vector of $-10^{\circ}$.

The chest radiograph showed mild cardiac enlargement, a prominent pulmonary artery shadow, and moderate pulmonary venous congestion.

At operation in April 1973 the intracardiac pressures (Table I) in the left atrium and right ventricle were raised; the left ventricular enddiastolic pressure was elevated. No pericardial lesion was detected; there was mild scarring of the epicardium of the right ventricle, but the coronary arteries were normal. The mitral valve (Fig. 2) showed fibrosis and degeneration of the anterolateral papillary muscle, rupture of the middle of the posterolateral cusp which contained large vegetations on its edges, and a small perforation in the anteromedial cusp.

There was also contusion and endocardial fibrosis of the left ventricular apex which contained three interventricular septal defects, the largest being about
$1 \mathrm{~cm}$ in diameter. Under a normothermic total cardiopulmonary bypass, the mitral valve was replaced with an unstented aortic homograft, and after excision of the scarred and fibrosed ventricular endocardium, the septal defects were repaired by $\overrightarrow{\bar{\rho}}$ approximation. Post-bypass intracardiac pressures

T A B L E I PREPERFUSION PRESSURES

\begin{tabular}{|c|c|c|}
\hline \multirow{2}{*}{ Site } & Systolic & \multirow{2}{*}{ Pressure $(\mathrm{mm} \mathrm{Hg})$} \\
\hline & Diastolic & \\
\hline \multirow{2}{*}{ Right atrium } & 4 & \multirow{4}{*}{ Mean $=34$} \\
\hline & 0 & \\
\hline \multirow{2}{*}{ Left atrium } & 80 & \\
\hline & & \\
\hline \multirow{2}{*}{ Right ventricle } & 70 & \multirow{6}{*}{$E D P=20$} \\
\hline & $\overline{3}$ & \\
\hline Left ventricle & 115 & \\
\hline Lent ventricic & 10 & \\
\hline \multirow[b]{2}{*}{ Aorta } & 110 & \\
\hline & $\overline{70}$ & \\
\hline
\end{tabular}

(Table II) showed a satisfactory haemodynamic state.

Postoperative progress was uncomplicated; thed excised mitral valve was sterile on bacteriologica $f_{D}$ culture. Progress up to February 1975 (22 months)? has been very satisfactory. 


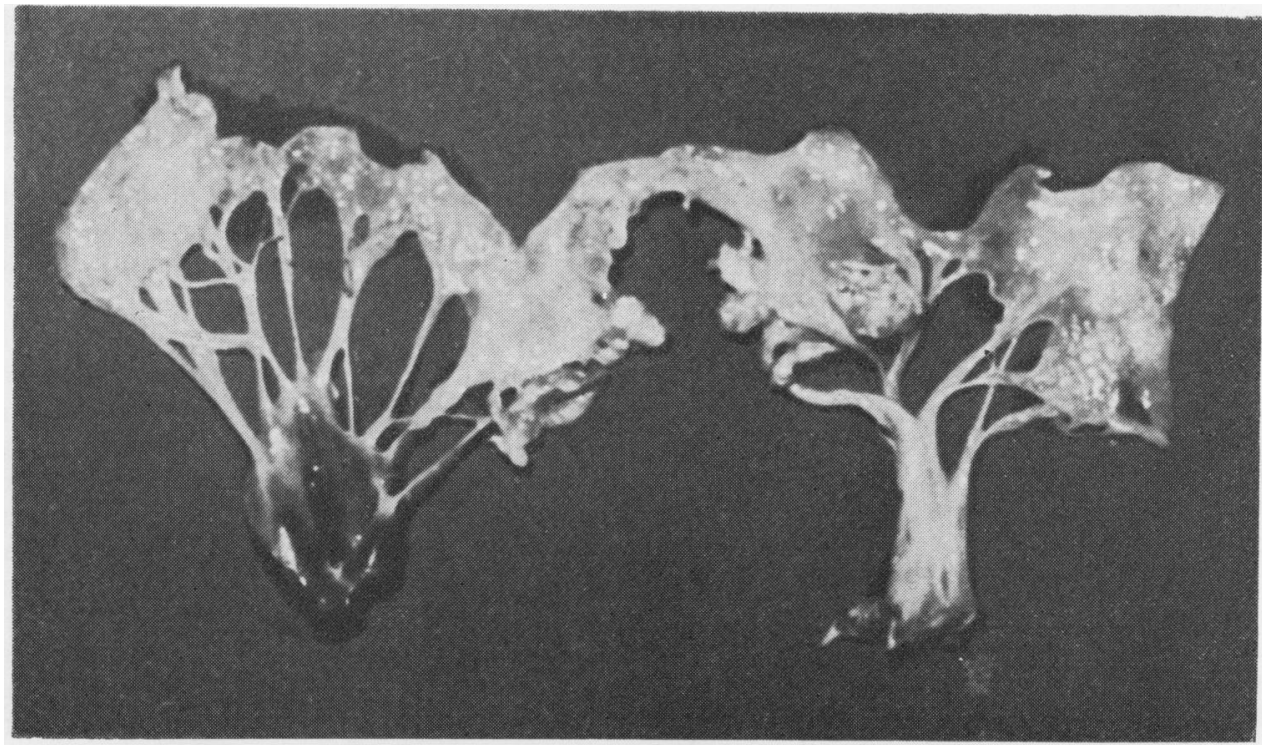

FIG. 2. Excised mitral valve with fibrosed anterolateral papillary muscle (right) and perforations of cusps containing vegetations.

T A B LE I I

POSTPERFUSION PRESSURES

\begin{tabular}{|c|c|c|}
\hline Site & $\frac{\text { Systolic }}{\text { Diastolic }}$ & Pressure $(\mathrm{mm} \mathrm{Hg})$ \\
\hline Right atrium & - & \\
\hline Left atrium & $\frac{10}{8}$ & \\
\hline Right ventricle & $\frac{28}{4}$ & \\
\hline Left ventricle & $\frac{95}{5}$ & $E D P=5$ \\
\hline Aorta & $\frac{95}{60}$ & \\
\hline
\end{tabular}

EDP $=$ end-diastolic pressure.

Note marked reduction in left atrial, right ventricular, and left ventricular end-diastolic pressures, indicating immediate improvement of the left ventricular function.

\section{DISCUSSION}

It is becoming increasingly evident that, though penetrating injuries of the heart and the great vessels are frequently reported, non-penetrating injuries of the heart and the great vessels are not as uncommon as they appear to be. From necropsy and clinical series, the incidence has been estimated at $10-75 \%$ in the presence of severe trauma, especially chest injuries.
The mechanism of the injury varies widely. Warburg (1940) recorded two cases of fist blows, 28 cases of falls and blows from objects, and only 16 (out of 57) cases that may be considered 'automobile'. It has been recognized that, though the majority of the injuries are sited on the thorax, injuries distant from the heart (for example, following a fall on the buttocks) may cause cardiovascular damage. The traumatic forces may be directed to the anterior aspect of the chest, or to the back, as occurs when a vehicle runs over a prostrate body or a heavy object falls on the back of the chest, as in the case described. Parmley et al. (1958) have accordingly categorized the traumatic forces under direct, indirect, bidirectional or compressive, decelerative, blast concussion, and combined. The severity of the traumatic force does not bear a direct relationship to the severity of the consequent cardiac injury. Out of 152 fatal cardiac ruptures caused by nonpenetrating chest injuries, Bright and Beck (1935) found fractures of the ribs in only 58 cases. Moreover, in a series of 250 blunt chest injuries, Arenberg (1943) found that cardiac damage occurred among cases without rib fracture. Similarly, the case described had severe cardiac damage without demonstrable chest wall injury. Cardiac injury may, therefore, occur in the absence of rib fractures, while serious cardiac damage is more likely to occur when the causative force is frontal and the heart is compressed between the sternum and spine (Pierce, Dabbs, and Rawson, 1958). 
PATHOLOGY OF TRAUMATIC CARDIAC LESIONS The pathology of lesions resulting from blunt cardiac injuries is variable. Schlomka (1934) produced ventricular tachycardia and fibrillation by direct blows to experimental animals but he could not demonstrate significant pathological changes in the myocardium at necropsy. However, Kissane et al. (1937) demonstrated cardiac injuries consisting of subepicardial and subendocardial haemorrhages, haemopericardium, cardiac necrosis, dysrrhythmias, ventricular fibrillation, cardiac standstill, and sudden death in experimental animals who received controlled non-penetrating injuries to the chest wall. The patient described in this paper developed traumatic mitral incompetence and ventricular septal defects. Mitral valve disease resulting from blunt trauma is rare. Warburg (1940), in his comprehensive review, reported very few cases of mitral valve disease; Parmley et al. (1958), in a large series of 546 cases of blunt cardiac injuries, reported no isolated mitral valve lesion and only eight cases of mitral valve damage associated with other cardiac lesions. In 1964, McLaughlin et al. reported two cases of mitral valve disease from blunt chest trauma and referred to only 18 previous cases in the English literature. Rupture, avulsion or haemorrhagic necrosis of the papillary muscle, as demonstrated in the case described in this paper, accounts for most of the traumatically produced mitral valve disease (McLaughlin et al., 1964; Goggin, Thompson, and Jackson, 1970; Schroeder et al., 1972).

In addition to mitral incompetence, traumatic ventricular septal defects were present in the case described. Rupture of the interventricular septum occurs more frequently than mitral valve damage following non-penetrating chest injury; it often occurs with rupture of one or more heart chambers. In 1935, Bright and Beck reported 11 instances of rupture of the interventricular septum in a series of 152 cardiac lesions following non-penetrating trauma. By 1958, there were 25 proven cases of interventricular septal rupture due to non-penetrating trauma reported in the literature, including one on which closure under hypothermia was attempted unsuccessfully. Campbell et al. (1959) reported the first successful repair (by Lillehei in 1955) of traumatic ventricular septal defect, and by early 1969 only 11 of the 47 patients with traumatic ventricular septal defect reported in the literature had been operated on (Scheinman et al., 1969). The ventricular septal defects in the case described were sited in the apical muscular portion; this finding conforms with those in most other reported cases. Two explanations of the mechanism of rupture of interventricular septum or papillary muscles have been put forward:
1. The initial damage of the nutrient vessels of the septum or papillary muscles results in infarction which progresses to liquefaction necrosis and $\overline{\bar{c}}$ perforation or rupture (Williams and Bullock,, 1961).

2. The heart is compressed during the vulnerable period of late diastole or early systole when. the ventricular chambers are full and the valves $\vec{\omega}$ are closed.

DIAGNOSIS In the case described, a heart murmurci was detected about two weeks after trauma. This:murmur was described as that of mitral regurgitation, $-\overrightarrow{-}$ which was confirmed by cardiac catheterization $\vec{\omega}$ seven years before bacterial endocarditis supervened.을 The murmurs of traumatic ventricular septal defect or mitral incompetence rarely appear soon after T, injury, but they are commonly detected some days or weeks later. This late appearance of heart murmuro supports the first explanation of the mechanism of rupture stated above. In most cases, abnormake electrocardiographic findings (especially supra-ô ventricular arrhythmias, conduction disturbances or $\square$ QRS abnormalities) may be the first signs of significant cardiac injury. Rosenthal, Parisi, and Nadas (1970) stated that the triad of chest trauma, systolici murmur, and an infarct pattern on the electro-市 cardiogram should suggest interventricular septa defect.

Patients with isolated mitral incompetence or ventricular septal defect may remain haemodynami cally well compensated for some period, and trau matic interventricular septal rupture may heal and close spontaneously (Rosenthal et al., 1970), depend ing on the size of the defect. But patients with eithe lesion who are developing congestive failure shouid have surgical correction under cardiopulmonary் bypass. The results of late surgical corrections of traumatic ventricular defects have been good; with associated mitral valve replacement, as in the case described, the result could be very satisfactory.

Frequent careful evaluation of the cardiovascular. system (including serial electrocardiograms) of patients recovering from non-penetrating ches trauma is essential for effective surgical managemen: of serious cardiac complications.

I should like to thank Mr. M. H. Yacoub and Dr. Walter Sommerville for permission to publish this case and foes their encouragement in the preparation of this paper.

\section{REFERENCES}

Arenberg, H. (1943). Traumatic heart disease: a clinica study of 250 cases of non-penetrating chest injuries and their relation to cardiac disability. Annals of Internal Medicine, 19, 326. 
Bright, E. F. and Beck, C. S. (1935). Nonpenetrating wounds of the heart. American Heart Journal, 10, 293.

Campbell, G. S., Vernier, R., Varco, R. L., and Lillehei, C. W. (1959). Traumatic ventricular septal defect: report of two cases. Journal of Thoracic and Cardiovascular Surgery, 37, 496.

Goggin, M. J., Thompson, F. D., and Jackson, J. W. (1970). Deceleration trauma to the heart and great vessels after road traffic accidents. British Medical Journal, 2, 767.

Kissane, R. W., Fidler, R. S., and Koons, R. A. (1937). Electrocardiographic changes following external chest injury to dogs. Annals of Internal Medicine, 11, 907.

McLaughlin, J. S., Cowley, R. A., Smith, G., and Matheson, N. A. (1964). Mitral valve disease from blunt trauma. Journal of Thoracic and Cardiovascular Surgery, 48, 261.

Moraes, R., Victor, E., Arruda, M., Cavalcanti, I., Raposo, L., Ricardo-Lagrecia, J., and Gomes, J. M. (1973). Ventricular septal defect following nonpenetrating trauma. Angiology, 24, 222.

Parmley, L. F., Manion, W. C., and Mattingly, T. W. (1958). Nonpenetrating traumatic injury of the heart. Circulation, 18, 371.

Pierce, E. C., Dabbs, C. H., and Rawson, F. L. (1958). Isolated rupture of the ventricular septum due to nonpenetrating trauma. Report of a case treated by open cardiotomy under simple hypothermia. Archives of Surgery, 77, 87.
Rosenthal, A., Parisi, L. E., and Nadas, A. J. (1970). Isolated interventricular septal defect due to nonpenetrating trauma. Report of a case with spontaneous healing. New England Journal of Medicine, 283, 338.

Scheinman, J. I., Kelminson, L. L., Vogel, J. H. (1969). Early repair of ventricular septal defect due to nonpenetrating trauma. Journal of Pediatrics, 74, 406.

Schlomka, C. (1934). Quoted by Arenberg, H. 1943. Experimentelle Untersuchungen uber den Einfluss stumpfer Brustkorb-traumen auf das Herz. Zeitschrift für die gesamte experimentelle Medizin zugleich Fortsetzung der Zeitschrift für experimentelle Pathologie und Therapie, 93, 751.

Schroeder, J. S., Stinson, E. B., Bieber, C. P., Wexler, L., Shumway, N. E., and Harrison, D. C. (1972). Papillary muscle dysfunction due to non-penetrating chest trauma. Recognition in a potential cardiac donor. British Heart Journal, 34, 645.

Warburg, E. (1940). Myocardial and pericardial lesions due to non-penetrating injury. British Heart Journal, 2, 271.

Williams, G. D. and Bullock, R. (1961). Traumatic ventricular septal defects. American Journal of Cardiology, 7, 277.

Requests for reprints to: C. H. Anyanwu, FRCS, Cardiothoracic Unit, Department of Surgery, University of Nigeria Teaching Hospital, Enugu, Nigeria. 